
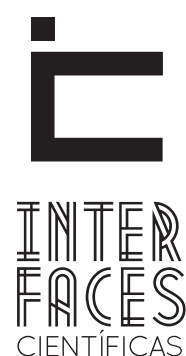

HUMANAS E SOCIAIS

\title{
EDUCAÇ̃̃̃O NÃO ESCOLAR, APRENDIZAGEM UBÍQUA E NOVAS FORMAS DE APRENDER
}

Kaio Eduardo de Jesus Oliveira

Cristiane de Magalhães Porto ${ }^{3}$

\author{
Daniella de Jesus Lima²
}

\section{RESUMO}

O presente trabalho propõe-se a discutir acerca das atuais concepções de comunicação entre os sujeitos culturais, bem como refletir sobre as formas de aprender diante do cenário da cultura digital, dando ênfase à aprendizagem ubíqua. Para tanto, tem-se como objetivo discutir a aprendizagem ubíqua e as formas de aprender possibilitadas pelos dispositivos digitais móveis. No intuito de elucidar essa reflexão, utilizou-se como metodologia para o estudo a pesquisa bibliográfica, nesta foi utilizado o aporte teórico de autores como Lúcia Santaella (2010 e 2013); André Lemos (2007, 2009 e 2013) e Valéria Vieira (2005). Os dispositivos móveis transformaram o processo comunicacional dos sujeitos culturais, de uma maneira que a aprendizagem por meio da educação formal tornou-se desinteressante para os discentes. Estes, equipados com smartphones, buscam, compartilham, trocam conhecimento, conteúdos, informações sem determinação de espaço e tempo. Nesse contexto, a escola não é o único espaço para a aprendizagem, o professor e o livro didático não são as únicas fontes de conhecimento, o tempo para aprender não é o tempo determinado pelos horários das grades curriculares. O conhecimento está disponível e acessível em múltiplas plataformas, e por meios dos dispositivos móveis os sujeitos aprendem de forma autônoma.

\section{PALAVRAS-CHAVE}

Tempo. Espaço. Dispositivos Móveis. Aprendizagem. 


\section{ABSTRACT}

This paper proposes to discuss about the current concepts of communication between cultural subject and reflect on ways of learning before the digital culture scene, emphasizing the ubiquitous learning. Therefore, we have discusses the ubiquitous learning and ways of learning made possible by mobile digital devices. To clarify this reflection, it was used as a methodology for studying the literature, this was used the theoretical contribution of authors such as Lucia Santaella (2010 and 2013); André Lemos (2007, 2009 and 2013) and Valeria Vieira (2005). Mobile devices transform the communication process of cultural subjects in a way that learning through formal education has become uninteresting to the students. These are equi- pped with smartphones, seek, share, exchange knowledge, content, information without determination of space and time. In this context, the school is not the only space for learning, the teacher and the textbook are not the only sources of knowledge, the time to learn is not the time determined by the timing of curricula. The knowledge is available and accessible on multiple platforms, and by means of the subject mobile devices learn autonomously.

\section{KEYWORDS}

Time. Space. Mobile devices. Learning.

\section{RESUMEN}

En este trabajo se propone debatir sobre los conceptos actuales de la comunicación entre el sujeto cultural y reflexionar sobre formas de aprendizaje antes de la escena de la cultura digital, haciendo hincapié en el aprendizaje ubicuo. Por lo tanto, tenemos que analizar el aprendizaje ubicuo y posibles formas de aprendizaje mediante dispositivos digitales móviles. Para aclarar esta reflexión, se utilizó como metodología para el estudio de la literatura, esto se utilizó la contribución teórica de autores como Lucia Santaella (2010 y 2013); André Lemos (2007, 2009 y 2013) y Valeria Vieira (2005). Los dispositivos móviles han transformado el proceso de comunicación de temas culturales de manera que el aprendizaje a través de la educación formal se ha convertido en poco interesante para los estudiantes. Estos están equipados con te- léfonos inteligentes, buscar, compartir, intercambiar conocimientos, contenidos, información sin la determinación del espacio y del tiempo. En este contexto, la escuela no es el único espacio para el aprendizaje, el maestro y el libro de texto no son las únicas fuentes de conocimiento, el tiempo para aprender no es el tiempo determinado por el calendario de los planes de estudio. El conocimiento está disponible y accesible en múltiples plataformas, y por medio de la materia dispositivos móviles aprender de forma autónoma.

\section{PALABRAS CLAVE}

Espacio. Tempo. Dispositivos móviles. Aprendizaje. 


\section{INTRODUÇ̄̃̃O}

A rapidez e o fracionamento da informação são características cada vez mais inerentes ao cotidiano dessa geração, atrelado a isso a escola tem se tornado cada vez mais um espaço distante de suas experiências cotidianas e a separação entre as práticas educativas que acontecem dentro e fora dela cresce, ainda mais, a partir da expansão do uso das tecnologias de comunicação móvel.

Se fora da escola, celulares, smartphones e outras tecnologias trazem a possibilidade de acesso às redes de amigos e de informação compartilhada, dentro das instituições de ensino formal, esse uso é, muitas vezes, negado, fortalecendo a condição histórica de "aluno" que apenas recebe a informação transmitida pelo professor, do sujeito que é constituído na relação com os artefatos de seu tempo.

A partir disso, é necessário repensar as novas formas de aprender possibilitadas pelo contato com esses dispositivos móveis. É fato que as instituições de ensino formal estão configuradas com um formato totalmente diferente daquele que compõem a realidade dos estudantes, principalmente, pelo momento de expansão das mídias digitais. Estas se desenham cada vez mais atraentes e ainda estão repletas de informação e conteúdo em qualquer hora e em qualquer lugar.

Com as mídias móveis, o acesso à informação e o fluxo da comunicação acontecem localmente, sem necessidade de estar em um ambiente formal de uma instituição educativa. Essa facilidade e praticidade de acesso a conteúdos informativos têm favorecido a consolidação de novos ambientes educacionais e novas formas de aquisição de informação e conhecimento.

Essa tecnologia está em ampla difusão no mundo, caracterizando uma nova fase da Cibercultura onde os objetos técnicos são sensíveis ao lugar e a outros objetos. Nesse processo é preciso pensar os processos educativos e as novas formas de aprender que os estudantes de hoje estão imersos. Com base no exposto, este artigo tem como objetivo discutir a aprendizagem ubíqua e as formas de aprender possibilitadas pelas mídias digitais móveis.

$\mathrm{O}$ texto apresenta duas seções e a conclusão. $\mathrm{Na}$ primeira seção apresenta-se como acontecem as relações comunicacionais entre os sujeitos imersos na cultura digital. Relações estas que acontecem de maneira destemporalizada (não há determinação de tempo) e deslocalizada (não há local específico) e que tem como finalidade o entretenimento, troca de informações e conhecimento, entre outras vertentes.

Em meio a essa realidade é que se enfatiza a aprendizagem ubíqua, acerca da qual se discute na segunda seção desta pesquisa. Percebe-se esta como a aquisição de conhecimento por meio desses dispositivos móveis, sem delimitação de tempo e espaço para que ocorra o processo de aprendizagem. Os conteúdos estão disponíveis e acessíveis a todo o momento e podem ser acessados de qualquer local por meio de qualquer um desses dispositivos.

O desenvolvimento desta pesquisa foi estimulado a partir das discussões no Grupo de pesquisa em educação tecnologia da informação e CiberculturaGETIC/CNPq. Sua elaboração se deu por meio de uma pesquisa bibliográfica, tendo como fontes principais, livros e artigos referentes à cultura digital e educação.

\section{MOBILIDADE, MÍDIAS DIGITAIS, ESPAÇOE TEMPO}

O estágio atual dos dispositivos móveis caracteriza uma nova faceta da Cibercultura. Nesse cenário, a conexão é on-line e instantânea e os estímulos vêm de toda parte. Atualmente, televisão, telefone celular, fone de ouvido, MP3, Twitter, Facebook, SMS, Whatsa- 
pp são tecnologias que não apenas integram o dia a dia das pessoas, mas mediam de diversas tarefas que são executadas por estas por meio desses dispositivos.

Atrelado a isso o fluxo de informações é formado por processos personalizados, a partir de associações em rede, onde qualquer um pode produzir, armazenar, processar e circular informações sobre formatos e modelos diferentes e os objetos técnicos, também, podem se comunicar entre si. Desse modo, se difundem o que Lemos (2007) chama de mídias pós-massivas, constituídas a partir da liberação do polo de emissão da comunicação e da conexão generalizada por meio de redes telemáticas.

Todas essas características específicas difundidas por dispositivos digitais móveis por meio da popularização atual dos smartphones e dos serviços baseados em localização têm provocado uma virada espacial nos processos comunicacionais e educativos, já que educação e comunicação estão entrelaçadas. Esses artefatos produzem uma realidade específica entre informação, comunicação, mobilidade, redes e espaço. Todavia, para se compreender seus impactos no dia adia é preciso discutir as concepções de espaço e tempo a partir delas.

É importante frisar que os dispositivos móveis não se limitam apenas aos smarthphones. Deve-se atentar para o fato de que todo equipamento que pode ser transportado com informação acessível em qualquer lugar é um aparelho/dispositivo móvel. Por meio deles a continuidade do tempo soma-se a do espaço (SANTAELLA, 2013).

As concepções sobre espaço sempre estiveram de alguma forma relacionadas à apropriação de uma área física ou a uma determinada estrutura materializada. Porém, a partir da Cibercultura muitas dessas concepções tornaram-se inapropriadas para conceituar a realidade. Afinal, o conceito de espaço deixou, em muitas situações, de ser entendido como estrutura física onde as coisas estão depositadas e passou a ser entendido como rede, que se produz, continuamente, pela dinâmica das associações e a ideia de tempo deixou de ser meramente cronológico e passa a complementar a de espaço.

Com a inserção das tecnologias digitais móveis no cotidiano dos sujeitos, tem-se acesso à internet em qualquer hora e de qualquer lugar. Enquanto que na primeira fase da internet acessava-se esta somente da escola, do trabalho, de casa. Nesse contexto, o lugar era apenas um simples detalhe no processo infocomunicacional.

A partir das mídias digitais móveis essa ideia de espaço e tempo estáticos se transformam. O lugar passa a ser peça fundamental na comunicação. André Lemos em seu livro A comunicação das coisas explica que:

[...] o espaço se constitui no espaçamento (associação em movimento) entre objetos e lugares. Da mesma forma, o tempo não é uma dimensão absoluta cronológica. Ele é simultaneidade da relação entre as coisas. Se não há mediação, relação de uma coisa com outra, não há tempo, não há espaço. Eles são, portanto, contingentes. (LEMOS, 2013, p. 177).

A partir do exposto, pode-se considerar então que o espaço desloca-se, tornando-se um "espaço-rede", composto pela dinâmica das ações dos humanos e dos não humanos. Essa mistura de dimensões, associação do real como o digital é chamado de espaços intersticiais ou híbrido, por Santaella (2008). Nessa reflexão acerca de espaços híbridos, Souza \& Silva (2006, p. 27) afirmam que:

Os espaços híbridos combinam o físico e o digital num ambiente social criado pela mobilidade dos usuários conectados via aparelhos móveis de comunicação. A emergência das tecnologias portáteis contribuiu para a possibilidade de se estar constantemente conectado a espaços digitais, de se "carregar" a internet onde que se vá.

A partir da articulação do espaço como espaço-rede, o conceito de lugar tornou-se fundamental e ressignificou-se, tornando-se heterogêneo e plural. La- 
tour (2012) afirma que tudo o que age em um lugar vem sempre de muitos tempos e lugares. Os lugares reúnem sempre agentes gerados em diversas temporalidades. Portanto, o lugar não é mais independente do contexto, nem um mero detalhe da ação. Com as mídias locativas, o lugar passa a ser o centro das atenções, constituído por meio da associação com outros lugares.

\section{APRENDIZAGEM UBÍQUA: NOVAS FORMAS DE APRENDER}

Para continuar essa discussão é importante demarcar o conceito de educação que aqui nos referimos e definir o sentido em que nos apropriamos da educação formal e da educação não formal. Sobre isso Vieira e outros autores (2005, p.21) nos esclarecem que,

[...] a educação enquanto forma de ensino-aprendizagem, pode ser dividida em três diferentes formas: educação escolar, formal, desenvolvida em escolas; educação informal, transmitida pelos pais, no convívio com amigos, em clubes, teatros, leituras e outras através de processos naturais e espontâneos; e a educação não-formal, que ocorre quando existe a intenção de determinados sujeitos de criar e buscar determinados objetivos fora da instituição escolar.

A vista disso, a educação não-formal que é a que centraliza a discussão desse texto pode ser definida como a que proporciona a aprendizagem de conteúdos de escolarização formal em espaços como museus, centros de ciências, ou quaisquer outros em que as atividades sejam desenvolvidas de forma bem direcionada, com o objetivo definido (VIEIRA ET AL., 2005, p. 21). Nesse sentido, configura-se então, novas formas de aprender em formatos abertos e mais flexíveis.

Partindo desta perspectiva, Santaella (2010, p. 3) argumenta que:

Processos de aprendizagem abertos significam processos espontâneos, assistemáticos e mesmo caóticos, atualizados ao sabor das circunstâncias e de curiosidades contingentes e que são possiveis porque o acesso à informação é livre e contínuo, a qualquer hora do dia e da noite. Por meio dos dispositivos móveis, à continuidade do tempo se soma a continuidade do espaço: a informação é acessível de qualquer lugar. É para essa direção que aponta a evolução dos dispositivos móveis, atestada pelos celulares multifuncionais de última geração, a saber: tornar absolutamente ubíquos e pervasivos o acesso à informação, a comunicação e a aquisição de conhecimento.

A difusão de dispositivos digitais móveis, cada vez mais acessíveis e presentes no cotidiano das pessoas, estão em ascensão atualmente nas discussões sobre educação. A difusão dessa mídia traz a tona questões que não são somente atuais, mas que, no entanto, precisam ser ressaltadas, já que, nas relações sociais os objetos técnicos sempre estiveram em segundo plano, mesmo sendo parte delas ao longo dos tempos.

Nos processos educativos isso não é diferente. $\mathrm{A}$ relação entre educação e tecnologia, apesar de ser um tema que está em pauta, sempre aconteceu, desde os povos primitivos que adotaram métodos para registros escritos antes da invenção do papel. Desde os tempos mais antigos, os educadores sempre buscaram introduzir ferramentas tecnológicas em seus ambientes educacionais para viabilizar a aprendizagem.

O avanço tecnológico, ao longo dos tempos e alavancado hoje por dispositivos e serviços móveis e digitais, torna a interação mediada pela tecnologia cada vez mais prática. Isso significa que o acesso a esses dispositivos sem a necessidade de conhecimentos técnicos por parte dos usuários facilita o acesso a conteúdos que antes eram disponibilizados em pouquíssimos espaços. À vista disso, qualquer pessoa que tenha um computador ou celular conectado à internet é capaz de acessar e produzir informação.

Nesse sentido, é preciso repensar as formas de aprender a partir desses dispositivos, já que por meio deles as maneiras de acessar a informação descentralizam-se. A escola deixa de ser o lócus central de aprendizagem, principalmente porque em boa parte das instituições formais de ensino o 
uso de telefones celulares é restrito e seu uso indiscriminado e associado ao lúdico.

Como afirma Barbero (2014), o contexto atual contempla uma sociedade fundada na aprendizagem contínua, de forma que a extensão educativa atravessa o espaço escolar, o tempo de aprender e o livro como fonte de conhecimento. Com a expansão do acesso aos dispositivos móveis, passou-se a ter uma sociedade voltada para a aprendizagem sem lugar, tempo e fonte de conhecimentos específicos. Por meio de um dispositivo móvel, tem-se acesso a conteúdo em qualquer lugar, a qualquer tempo e em qualquer plataforma.

Com a adoção das tecnologias móveis, principalmente, fora das salas de aula das instituições formais de ensino, a transmissão do conhecimento vem se tornando um grande desafio para uma geração de professores que estudou e aprendeu a ensinar em uma época anterior a esta. Em um período que não contava com recursos de interação e colaboração capazes de conectar, estudantes e a sociedade, independente de formação, cultura ou nação onde vivem.

Couto (2013) defende que qualquer processo de ensino e aprendizagem se mostra mais rico e interessante em meio a essas trocas contínuas. 0 que faz com que o ambiente formal da escola torne-se cada vez mais obsoleto. Ou seja, com a liberação do polo de emissão e por meio da autopublicação todos podem colaborar com releituras e lançar mão de novas ideias e pensamentos. Ensino e aprendizagem acontecem juntos, mirando-se e dialogando entre si por meio das diversas tecnologias disponíveis na sociedade contemporânea.

Contudo, o acesso às mídias digitais, também, contribui nesse processo, com o acesso prático a internet. Isto é, faz com que algumas práticas antes vivenciadas somente dentro das quatro paredes da escola tomem outras perspectivas. A aprendizagem, por exemplo, que antes somente era considerada quando acontecia dentro da escola, hoje pode acontecer a qualquer hora em qualquer lugar graças à ubiquidade delas. Couto (2013, p. 2) explica que "onde há pessoas conectadas, tem ensino e aprendizagem mediados por tecnologias digitais". 0 autor, ainda assegura que:

0 professor não é mais aquele que transmite um determinado saber pronto. Ser professor na cultura digital implica coordenar, orientar, incentivar a aprendizagem calaborativa e cada vez mais personalizada. Não se trata mais de uma mesma tarefa para todos num determinado espaço e tempo. 0 professor agora é aquele que coordena as atividades em torno de algum problema ou de determinados problemas. (COUTO, 2013, p. 2).

Os usos cada vez mais frequente das mídias digitais móveis nos processos de ensino e aprendizagem estão mudando radicalmente o modo como se entende a educação. 0 importante não é perceber que o aprendizado se dá por meio de ações continuadas, centralizadas em um ambiente e apresentadas pelo professor, dentro de uma sala de aula tradicional.

Entendido o papel singular que os veículos de comunicação passaram a exercer no mundo contemporâneo, agora com o aporte dos novos meios disponibilizados pela informática, pelos sistemas digitais, pelas redes de computadores, e que orientam uma revolução nos diferentes âmbitos formal, tenha se recolocado numa perspectiva diferenciada e que requisita, de maneira crescente, o estreitamento dialógico com informações e conhecimentos gerados em fontes indiretamente escolares. (CITELLI, 2004, p. 137).

A prática de construção de conhecimento de forma participativa e colaborativa cresce entre os sujeitos participantes desse novo cenário da comunicação. O cenário educacional transforma-se, os sujeitos passam a ser autores/autônomos de/na sua própria aprendizagem. A educação, nesse cenário apresentado pela cultura digital, deve ter docentes conscientizados de que, de diante do exposto, eles são apenas mediadores da aprendizagem. 0 aluno imerso na realidade dos dispositivos móveis deve ser orientado e livre para buscar e construir seu conhecimento na diversidade de meios disponíveis. 
Nesse contexto, dentro das discussões apresentadas sobre a descentralização da educação escolar e a possibilidade de se desenvolver uma educação "não-escolar", mais flexível, mais acessível, percebe-se que a aprendizagem torna-se mais democrática e que permite aos sujeitos explorar muitas possibilidades de ensino-aprendizagem. De forma que estes ao tempo que podem consumir conteúdos e contribuir com sua aprendizagem, pode compartilhar conteúdo, e dessa forma, contribuir com a aprendizagem do outro sujeito imerso nesse contexto.

Acerca disso, Santaella (2013) nos apresenta a perspectiva da aprendizagem ubíqua, entre outros aspectos, possibilitada pelas tecnologias digitais e de conexão contínua e que afetam diretamente a formas de ensinar e aprender. "Essa conectividade intensifica a colaboração em tempo real ou interatividade instantânea, que pode permitir melhores tomadas de decisões” (SANTAELLA, 2013, p. 292).

Em consideração ao que elucida a autora, essas tecnologias de conexão contínua estão relacionadas a redes móveis, podendo haver comunicação entre sujeitos que estejam presentes em espaços distintos. Diante disso, compreende-se a aprendizagem ubíqua, esta surge com a disseminação dessas tecnologias móveis. Com essas tecnologias, torna-se ubíquo o acesso aos diversos tipos de conteúdo, a comunicação entre os sujeitos, e consequentemente, a aprendizagem, seja de conteúdo formal ou informal.

A autora, ainda, enfatiza que embora possa se enquadrar em modelos de educação informal, a aprendizagem ubíqua constitui-se em um tipo específico, quando comparado aos modos pelos quais a aprendizagem informal desenvolvia-se antes do advento da mobilidade. Embora possua diversas semelhanças à versão ubíqua, também, não se confunde com os modelos de e-learning (aprendizagem em ambientes virtuais) e $m$-learning (aprendizagem móvel) (SANTAELLA, 2013).

\section{CONSIDERACŌES FINAIS}

Nessa problemática discutida, caracterizada como uma fase da Cibercultura, a informação chega a todo o momento, descontextualizada e muitas vezes truncada, inaugurando um novo jeito de compreender o mundo e de se relacionar ao conhecimento, em uma sociedade onde os novos dispositivos tecnológicos assumem um papel principal na vida do indivíduo é necessário repensar não apenas o modo de redimensionar práticas educacionais.

Dentro desse contexto, torna-se imprescindível que a figura do professor se apodere das mídias digitais, sejam elas locativas ou não, visando rever sua prática e compreensão de uma mudança que não é pontual, mas que acontece a todo o momento, redefinido papéis e novas formas de pensar.

A liberação polo de emissão que promoveu a autopublicação é a prova de que, em rede, todos podem ser emissor e receptor ao mesmo tempo. Entender que seres e objetos atuam juntos para retirar os véus das práticas educativas contemporâneas é um dos caminhos que podem ser trilhados, cada um com sua história e sua perspectiva de que o aprendizado hoje acontece de maneira simultânea e não separadamente como algumas vezes pensou-se ocorrer.

Portanto, entende-se que ao discutir a educação a partir das novas formas de aprender, articulados não necessariamente a partir de um currículo escolar, mas propiciados por tecnologias móveis, observou-se como há deslocamentos e redefinições no processo de educar e aprender. Há um novo desenho no quadro da sociedade em rede quando o aprender a aprender processa-se localmente dentro de uma rede onde a informação circula e faz-se texto, redefinindo espaços e ações.

É perceptível que toda essa circulação de novos dispositivos de comunicação inaugura uma maneira de se pensar a educação não escolar. Tal 
aspecto oferece um novo olhar, evidenciando as investigações que estão sendo efetuadas nas mais diversas áreas do conhecimento, dando suporte para não apenas conhecer novas formas de pensar o educar, mas também tentar entender algumas das suas especificidades diante da conectividade social e em rede.

Estudar a educação na atualidade não é tarefa simples, principalmente quando se propõe discutir a relação entre educação e tecnologias da informação e comunicação. Alguns intelectuais têm se preocupado em mostrar que é possível desfazer a dicotomia que compõe o cenário educativo atual e superar a ideia da escola do século XIX, professores do século XX e alunos do século XXI.

Embora essa ideia pareça um tanto quanto exagerada pode em muitos aspectos ser atrelada a relação escola-professor-aluno. Principalmente quando consideramos que o modelo que a escola e grande parte das instituições formais de educação ainda adotam não corresponde com a realidade vivida por parte de seus alunos, em especial quando é sabido que inúmeros professores continuam a fortalecer a desgastada ideia de professor que "sabe" e aluno que "aprende".

Essas novas formas de aprender estão relacionadas ao acesso a conteúdo informacional da web, a qualquer hora de qualquer lugar, a interação com outros indivíduos de forma instantânea, a possibilidade de consumir e produzir conteúdo etc. Dessa forma, a escola que ao longo dos anos foi a principal responsável pelo processo de ensino-aprendizagem entra em crise.

Com isso, a educação formal cada vez mais deixa de ser atrativa, pois os ambientes fora destas estão compostos com vários dispositivos que permitem o acesso prático e rápido aos mais diversos tipos de conteúdo. Portanto, é necessário repensar as práticas ainda utilizadas e adotar novas concepções do que é ensinar e o que é aprender na atualidade, assim, o que se tem chamado de aprendizagem ubíqua vem para fazer pensar sobre essas questões emergentes, e agregar potencialidades a educação escolar.

\section{REFERÊNCIAS}

BARBERO, Jesús Martín. A comunicação na educação. Tradução: Maria Immacolata Vassallo de Lopes e Dafne Melo. São Paulo: Contexto, 2014.

CITELLI, Adilson. Comunicação e educação: a linguagem em movimento. 3.ed. São Paulo: Senac, 2004.

COUTO, Evaldo Souza. Educação 3.0 é a tecnologia que integra pessoas. Disponível em: <http://porvir. org/porfazer/educacao-3-0-e-tecnologia-integra-pessoas/20130326>. Acesso em: 11 set. 2014.

LATOUR, B. Reagregando o Social. Bauru, SP: EDUSC/ Salvador, BA: EDUFBA, 2012.

LEMOS, André. A Comunicação das coisas: Teoria ator-rede e cibercultura. São Paulo: Annablume, 2013.

LEMOS, André; Josgrilberg, Fabio. Comunicação e mobilidade: aspectos socioculturais das tecnologias móveis de comunicação no Brasil. Salvador: EDUFBA, 2009.

LEMOS, André. Mídias locativas e territórios informacionais. Disponível em: <http://www.facom.ufba.

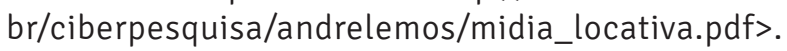
2007. Acessado em: 12 set. 2014.

SANTAELLA, L. A aprendizagem ubíqua substitui a educação formal? 2010. Disponível em: <http://revistas.pucsp.br/index.php/ReCET/article/ view/3852/2515>. Acesso em: 10 mar. 2015.

SANTAELLA, L. Comunicação ubíqua: repercussões na cultura e na educação. São Paulo: Paulus, 2013. 
SOUZA; SILVA, Adriana. Do ciber ao híbrido: tecnologias móveis como interface dos espaços híbridos. Porto Alegre: Sulina, 2006.
VIEIRA, Valéria; BIANCONI, Lucia M. e DIAS, Monique. Espaços não formais de ensino e o currículo de ciências Revista Ciência e Cultura Educação não-formal, São Paulo, n.4, ano 57, out-dez. 2005. p.21-23. 
